\title{
On the specific heat and conductivity of bodies
}

\section{Morisot}

To cite this article: M. Morisot (1880) On the specific heat and conductivity of bodies, Philosophical Magazine Series 5, 9:57, 386-389, DOI: 10.1080/14786448008626858

To link to this article: http://dx.doi.org/10.1080/14786448008626858

曲 Published online: 28 Apr 2009.

Submit your article to this journal $2 \pi$

Џ Article views: 2

Q View related articles $₫$ 
of the Shap blocks was due to floating ice, and referred this to the landice crossing the Pennine chain consequent upon greater snow-interception from the progress of the rise; and to the same cause he referred the drift which rises high on the eastern slope of the Pennine ridge north of the Aire. To this crossing of the ice having diverted first a part and then the whole of the ice-supply of the Chalky-clay glacier, he attributed first the shrinking of that glacier into the valleys in East Anglia, and afterwards its dissolution by the agencies always rife in the Greenland ice (but which are there balanced by continual reinforcement), when by this diversion its reinforcement by ice from the Pennine chain ceased. The purple clay of Holderness, being thus in its lowest part in Holderness coeval with the valley. formed portion of the Chalky Clay of Norfolk and Suffolk (or "third Boulder-clay" of Harmer), was the moraine of this invading ice, which, after crossing at Stainmoor, divided against the eastern moorlands of Yorkshire; and one branch going north of these moorlands through the valley of the Tees, sent off an arm down their eastern flank, the moraine from which is the narrow belt of purple clay which skirts the Yorkshire coast north of Holderness, and spreads out wider in Holderness. This arm from the Chalkyclay ice not having, in consequence of the westerly increment of depression, descended the eastern slope of the Wolds, found sea then covering the basement clay of Holderness, in which sea it stopped between the Humber and the Wash, by means of which the lower part of the purple clay up to the level of about 150 feet, contains intercalated in it beds of sand and gravel, and contains shells and shell-fragments, as does the Lancashire clay similarly extruded beneath the sea. The other branch came south along the western fiank of the east moorlands and through the Vale of York, where it ended, and became stationary in the sea as this entered the Trent system on the final dissolution of the chalky-clay glacier.

The author discovers no trace of any thing like the intercalation of warm periods up to the stage with which he concludes this part of his memoir; and leaves the description of the later beds, as well as an examination how far arboreal vegetation and the coexistence of Pachyderms and Proboscideans can bo reconciled with the contiguity of extensive land-ice, for the concluding part of it.

\section{Intelligence and Miscellaneous Articles.}

\section{ON THE SPECIFIC HEAT AND CONDUCTIVITY OF BODIES.}

BY M. MORISOT.

HAVE the honour to present to the Academy the general method and the principal experimental characters of a study which I have commenced upon specific heat and conductivity.

Suppose in the centre of an enclosure kept at $0^{\circ}$ a body which is a sufficiently good conductor to be admitted as homothermous-that is to say, of equal temperature in all its parts. I. call that temperature $x ; \mathrm{F}$ is the thermal capacity of the body, $\rho$ the amount of heat which it loses in a second for an excess of $1^{\circ}$ above the sur- 
rounding temperature on account of radiation, contact of the air, and of the supports.

Into this first body I introduce a second, which I suppose also homothermous. Let $y$ be its temperature, $\mathbf{C}$ its thermal capacity, $\epsilon$ its loss of heat per second for $1^{\circ}$ of excess at all the points where it is not in contact with the first body, $\lambda$ its loss at all points where it is in contact with the first body (this will be the external conductivity).

The immersion of the second body in the first will cause the temperatures $x$ and $y$ to vary according to the following differential equations :-

$$
\begin{aligned}
& -\mathrm{C} \frac{d y}{d t}=\lambda(y-x)+\epsilon y ; \\
& +\mathrm{F} \frac{d x}{d t}=\lambda(y-x) \rho x .
\end{aligned}
$$

Integration gives for $x$ and $y$ the functions :-

$$
\begin{aligned}
& x=\mathrm{M} e^{-m t}+\mathrm{N} e^{-n t} ; \\
& y=\mathrm{P}^{-m t}+\mathrm{Q} e^{-n t} .
\end{aligned}
$$

Observation of the course of the temperatures will give the quantities $\mathrm{M}, \mathrm{N}, \mathrm{P}, \mathrm{Q}, m, n$-with which we obtain

$$
\begin{aligned}
\frac{\mathrm{C}}{\mathrm{F}} & =\frac{-\mathrm{MN}}{\mathrm{PQ}}, \ldots \ldots \ldots \ldots \ldots \ldots \ldots \ldots \ldots \ldots \ldots \\
\overline{\mathrm{E}} & =\frac{-(n-m) \mathrm{MN}}{\mathrm{MQ}-\mathrm{NP}}, \ldots \ldots \ldots \ldots \ldots \\
\frac{\rho}{\mathrm{F}} & =\frac{m \mathrm{M}(\mathrm{Q}-\mathrm{N})-n(\mathrm{P}-\mathrm{M})}{\mathrm{MQ}-\mathrm{NP}}, \ldots \ldots \ldots \ldots \\
\frac{\epsilon}{\mathrm{C}} & =\frac{m \mathrm{P}(\mathrm{Q}-\mathrm{N})-n \mathrm{Q}(\mathrm{P}-\mathrm{M})}{\mathrm{MQ}-\mathrm{NP}}, \ldots \ldots \ldots
\end{aligned}
$$

A second experiment, in which, $\mathbf{F}$ remaining constant, $\mathrm{C}$ will have been augmented by a known quantity $k$, will give

$$
\frac{\mathrm{C}+k}{\mathrm{~F}}=\frac{-\mathrm{M}, \mathrm{N}}{\mathrm{P}, \mathrm{Q}}, \ldots \ldots \ldots \ldots \ldots \ldots
$$

and, with (1), permit the calculation of $\mathrm{F}$ and $\mathrm{C}$.

If the immersed body is not homothermous, I suppose it (for simplicity) of a cylindrical form, and replaced by two concentric bodies :- the one exterior, having in all its points the temperature $z$ of the surface of the real body; the other interior, its temperature $y$ suitably chosen in order that the sum of these bodies may replace the real body in its effects upon the exterior body. This second case, which I will call dithermy, will give three equations instead of two. The calculations will be longer, but not more complicated; and they will furnish, besides the physical unknown quantities of the preceding problem, the measure of the internal conductivity of the real body.

In order to approximate to the conditions assumed in this method, certain experimental arrangements are necessary :- 
(1) Instead of noting and utilizing merely the initial temperatures and that called final or stationary $(i, e$. the maximum of $x)$, I had, by observations sufficiently close and sufficiently long-continued, to follow the course of the temperatures in the body which was receiving and in that which was losing heat.

(2) Instead of observing only, as in the method called the cooling method, the temperature of the central parts of the hot body, I was obliged to add, near the surface, a second thermometer, giving the temperature of the outer zone.

I employ as the body receiving heat (as calorimeter) a brass cylinder admitting the immersed body into a cavity passing along its axis. Another small cavity, made in the pretty thick wall of the calorimeter, receives, together with a very inconsiderable known weight of water, the reservoir of the thermometer which will give the temperature $x$. The calorimeter rests, by three pointed feet, on the cork bottom of a larger metallic cylinder blackened inside and surrounded by melting ice.

The body under experiment, liquid or pulverulent, is placed in a tube of thin glass with a fiat bottom, fitting with very gentle friction into the central cavity of the calorimeter. The two thermometrical reservoirs are entirely surrounded by the body, the upper surface of which scarcely exceeds them and is flush with the brim of the calorimeter. This body being some degrees hotter than the calorimeter, I effect the immersion, and continue the readings, alternating them always in the same order, from minute to minute for each thermometer.

Before any numerical determination I wished to control the method by a few results in some known cases. I took, for example, as hot bodies some determined weights of distilled water, retaining always the same calorimeter. Twelve experiments gave as the mean result :-

grams.

Calorimeter and its thermometer, reduced to water . .. $19 \cdot 527$

Immersed portion of the tube, with its two thermometers 1.836

I have also drawn up the following comparative Table:-

\begin{tabular}{|c|c|c|c|}
\hline \multicolumn{2}{|l|}{$\begin{array}{l}\text { Weight of water } \\
\text { employed. }\end{array}$} & $\begin{array}{l}\text { Calculated value } \\
\text { of } \frac{C}{1} \text {. }\end{array}$ & $\begin{array}{l}\text { Experimental value } \\
\text { of } \frac{\mathrm{MN}}{\mathrm{DO}} \text { for each case. }\end{array}$ \\
\hline \multicolumn{2}{|l|}{ grams. } & & 0.70713 \\
\hline \multirow[t]{2}{*}{$12 \cdot 0$} & & $0 \cdot 70853$ & $0 \cdot 70870$ \\
\hline & & & $\begin{array}{l}0.70604 \\
0.75878\end{array}$ \\
\hline \multirow[t]{2}{*}{$13 \cdot 0$} & $\ldots$ & 0.75975 & 0.75987 \\
\hline & & & $0 \cdot 76467$ \\
\hline $13 \cdot 5$ & $\ldots \ldots$ & 0.78536 & 0.78700 \\
\hline \multirow[t]{2}{*}{$14 \cdot 0$} & $\ldots \ldots$ & 0.81098 & 0.81168 \\
\hline & & & $0 \cdot 86446$ \\
\hline \multirow[t]{2}{*}{$15 \cdot 0$} & $\ldots \ldots$ & 0.86220 & 0.85476 \\
\hline & & & 0.8 \\
\hline
\end{tabular}

In another series of experiments, different weights of mercury 
gave for its specific heat numbers presenting an error of at most 0.00061 .

I shall continue the investigation, applying the method to chemically pure substances, and determining their conductivity.Comptes Rendus de l'Académie des Sciences, April 5, 1880, t. xc. pp. 814-817.

\section{NOTE ON SUPERNUMERARY RAINBOWS. BY CH. MONTIGNY, MEMBER OF THE ROYAL ACADEMY OF BELGIUM.}

"When a rainbow is very brilliant, there are often seen inside of the interior and outside of the exterior bow coloured bands, which are designated secondary, supplementary, or supernumerary bows: immediately after the violet, red is distinguished, then green and violet. Sometimes these colours are repeated several times in the same order along the inner margin of the principal bow ; they appear more rarely outside of the second bow." M. Daguin, from whom I borrow these statements, adds that the supernumerary bows are only seen in the culminating portions of ordinary rainbows, and only when the altitude of the latter is considerable; no traces are seen of them near the horizon*.

Kaemtz, in his Traité de Météorologie, states the same particulars, from Langwith and other observers, who have never noticed supplementary rainbows near the parts of the principal bow in the vicinity of the earth.

Contrarily to these facts, I have recently had an opportunity of observing some supernumerary rainbows which were visible only at the lower extremities of the principal bow. The circumstances were, perhaps, exceptional ; but it is important to make them known.

On the 30th of August last, after a rainy day, I was with some other persons in the vicinity of Rochefort a little before sunset. A few moments after a fresh shower of short duration we remarked in the east, in which direction the rain continued, two ordinary rainbows. The colours of the principal bow lost some of their brightness in the lower regions of the air. These were sensibly darkened up to a certain height by a misty tinge, forming a broad zone perfectly distinct from the rain-cloud entirely above it, upon which the two bows appeared brighter. Moreover, at the inner side of each lower extremity of the inner bow, and consequently near the ground, four supernumerary rainbows could be distinguished, which appeared to rise on each side into the misty zone of the air to about one third of the altitude of the inner bow. The colours of these eight supernumerary portions possessed but little brightness : the red and a dark violet were alone distinct. I observed no supplementary bow outside of the large bow.

In this observation, which took place twenty minutes before the disappearance of the sun below the horizon, the production of supernumerary bows at the extremities, and not at the culminating portion, of the principal bow, constitutes a manifest exception to the facts hitherto observed. This exception can be explained by the circumstances which accompanied the observation, as we shall see.

- Traité de Physique, 3e édition, t. iv. pp. 284, 445. 